\title{
Faster Payments: Market Structure and Policy Considerations
}

No. $17-4$

\section{Aaron Rosenbaum, Garth Baughman, Mark Manuszak, Kylie Stewart, Fumiko Hayashi, and Joanna Stavins}

\begin{abstract}
:
The U.S. payments industry is in the process of developing ubiquitous, safe, faster electronic solutions for making a broad variety of business and personal payments. How this market for faster payments will evolve will be shaped by a range of economic forces, such as economies of scale and scope, network effects, switching costs, and product differentiation. Emerging technologies could alter these forces and lead to new organizational arrangements or market structures that are different from those in legacy payment markets to date. In light of this uncertainty, this paper examines three hypothetical market structures that may emerge: a dominant operator environment, a multi-operator environment, and a decentralized environment. Each of these market structures has different implications for the public policy objectives of efficiency, safety, and ubiquity. The paper also considers tools to promote positive outcomes in each market structure.
\end{abstract}

Keywords: faster payments, market structure, competition, payment system improvement, public policy, retail payments.

\section{JEL Codes: D4, G2, L1, E42}

Aaron Rosenbaum is a Senior Financial Services Analyst in the Retail Payments Section, Garth Baughman is an Economist in the Payment Systems Studies Section, Mark Manuszak is a Manager and Principal Economist, Payment System Studies, in the Payment System Studies Section, and Kylie Stewart is a Manager in the Retail Payments Section, all in the Reserve Bank Operations and Payment Systems Division of the Board of Governors of the Federal Reserve System. Fumiko Hayashi is a Senior Economist in the Economic Research Department of the Federal Reserve Bank of Kansas City. Joanna Stavins is a Senior Economist and Policy Advisor in the Research Department of the Federal Reserve Bank of Boston; her email address is joanna.stavins@bos.frb.org. Aaron Rosenbaum, whose email address is aaron.r.rosenbaum@frb.gov, is the corresponding author.

The authors would like to thank Jeff Marquardt, Susan Foley, David Mills, Bob Hunt, Julia Cheney, Zhu Wang, and John Weinberg for their contributions and assistance.

The views expressed in this paper are those solely the responsibility of the authors and should not be interpreted as reflecting the views of the Federal Reserve Bank of Boston, the Board of Governors of the Federal Reserve System, the Federal Reserve Bank of Kansas City, or anyone else in the Federal Reserve System.

This paper, which may be revised, is available on the web site of the Federal Reserve Bank of Boston at http://www.bostonfed.org/economic/current-policy-perspectives/index.htm.

This version: September 21, 2017. This versios is also published as "Faster Payments: Market Structure and Policy Considerations," Finance and Economics Discussion Series 2017-100, https://doi.org/10.17016/FEDS.2017.100. 
Authors' note: This paper reports on a research effort by Federal Reserve staff to examine market structure implications in the still-emerging faster payments market. The analysis and conclusions in this paper are those of the authors and do not indicate official positions of the Board of Governors or Federal Reserve System. Although this paper offers several considerations regarding the U.S. faster payments market, it does not make specific policy recommendations or provide a view on the potential roles, including service provider or other roles, that the Federal Reserve may play in this market. ${ }^{2}$ Given the nascent state of the faster payments market, many of the matters discussed in this paper are not yet settled. The paper is intended to provide background and a framework for future dialogue and research in this area.

\footnotetext{
${ }^{2}$ In September 2017, the Federal Reserve published a paper identifying updated tactics it will pursue to help improve the speed, safety and efficiency of the U.S. payment system. As discussed in that paper, the Federal Reserve plans to explore and assess the need, if any, for Federal Reserve engagement as a service provider, beyond providing settlement services, to support faster payments and will communicate the results of its assessment through a forthcoming publication. See Federal Reserve System (2017), Strategies for Improving the U.S. Payment System: Federal Reserve Next Steps in the Payments Improvement Journey, September 6, https://www.federalreserve.gov/newsevents/pressreleases/files/other20170906a1.pdf.
} 


\section{Table of Contents}

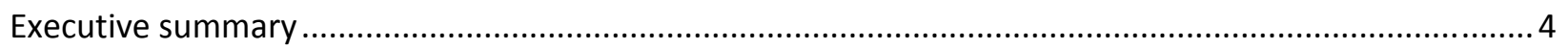

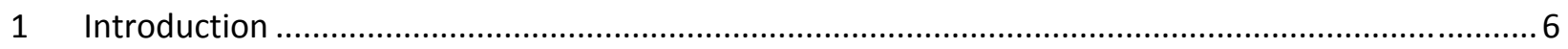

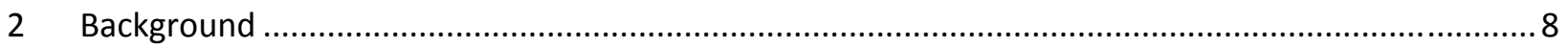

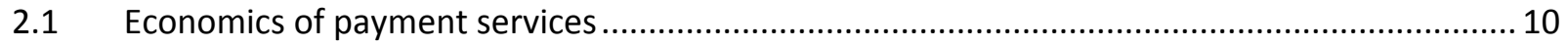

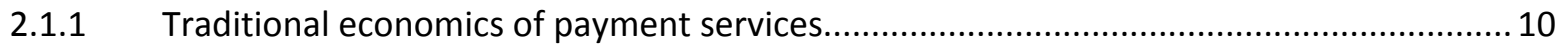

2.1.2 Implications of technological change for the economics of payment services .................13

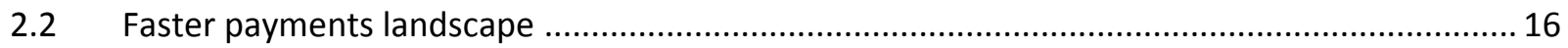

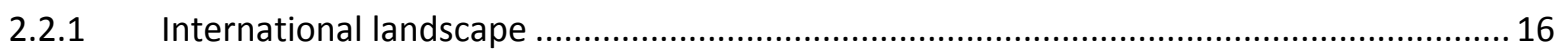

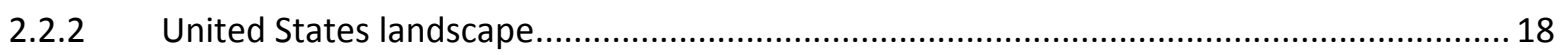

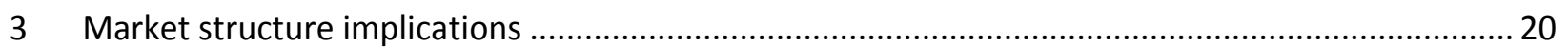

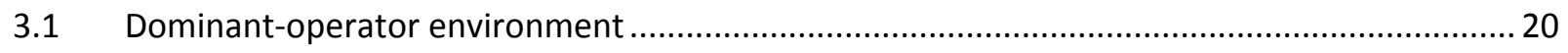

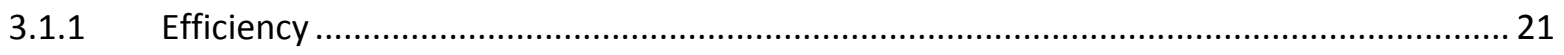

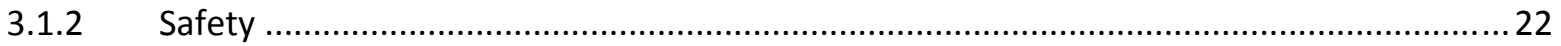

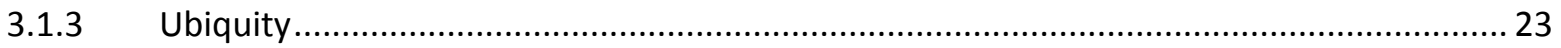

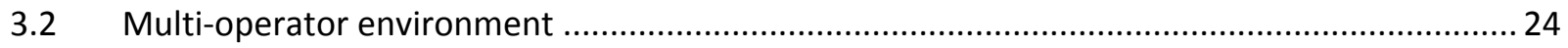

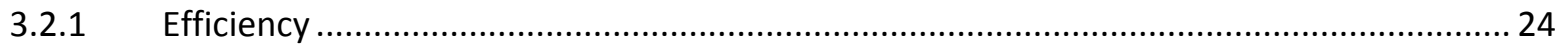

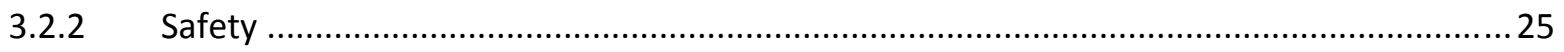

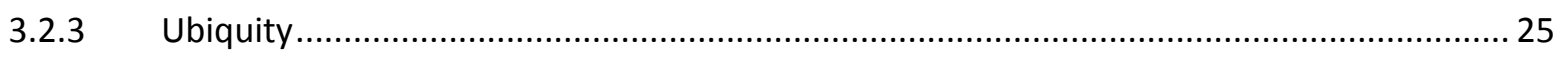

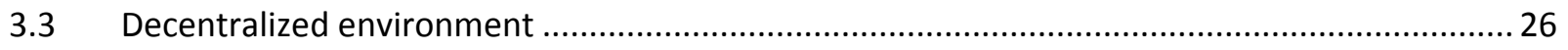

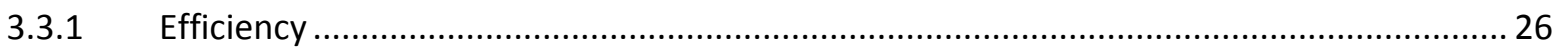

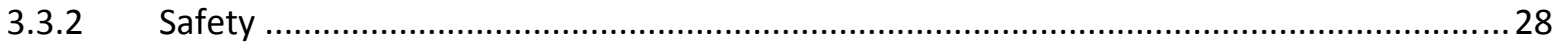

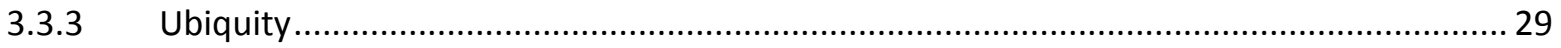

4 Considerations for promoting outcomes in line with policy objectives ......................................... 30

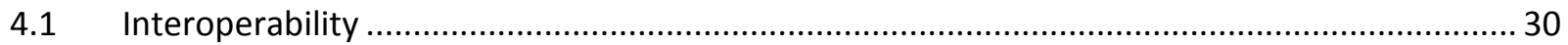

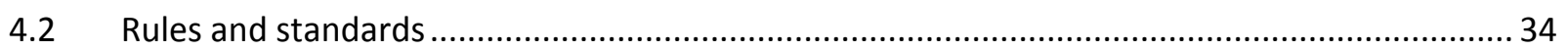

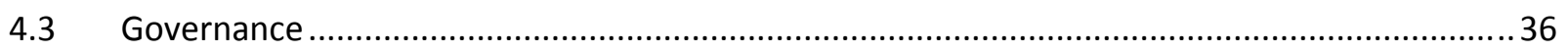

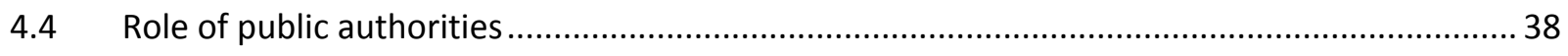

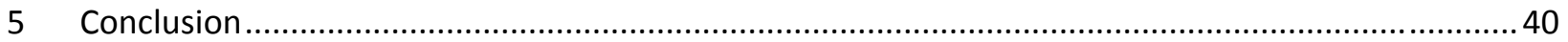




\section{Executive summary}

The U.S. payments industry is in the process of developing ubiquitous, safe, faster electronic solutions for making a broad variety of business and personal payments. Although a few private-sector firms are currently implementing new faster payments platforms, it is still uncertain how the market for faster payments will evolve in the long run.

As they did for legacy payment markets, economic forces such as economies of scale and scope, network effects, switching costs, and product differentiation will help shape the market for faster payments. Emerging technologies, however, could alter these forces and lead to new organizational arrangements or market structures. Various other factors, including industry and public-sector efforts, will also influence the structure of the faster payments market.

In light of this uncertainty, this paper examines three hypothetical market structures that may emerge: a dominant-operator environment, a multi-operator environment, and a decentralized environment. Each of these market structures has different implications for the public policy objectives of efficiency, safety, and ubiquity. In particular, outcomes in the faster payments market will depend on the degree and allocation of market power among participants, which in turn may depend on factors such as available substitutes or ease of market entry.

In the dominant-operator environment, provision of faster payments by a large operator that serves the vast majority of the market may result in productive efficiencies due to scale and scope economies. However, the dominant operator may lack competitive discipline on prices and service quality. Difficulties with market fragmentation would not arise in this environment, but high fees may reduce adoption, posing challenges to ubiquity. Additionally, a dominant operator may be well positioned in certain ways to promote safety but may concentrate operational or other risks. Moreover, a lack of competitive pressure leads to mixed effects on innovation.

In the multi-operator environment, multiple operators coexist, but none has the vast majority of the market share. Competition among operators in this environment may help mitigate market power concerns associated with the dominant-operator environment. Although competition may enhance efficiency and ubiquity goals, multiple operators replicate fixed infrastructure costs and may lead to a fragmented market, inhibiting these goals. While redundancy across multiple operators can enhance resiliency, coordinating safety measures across operators could be costly or difficult.

In the decentralized environment, a traditional operator that integrates many aspects of payment production - such as clearing, settlement, and establishing rules - does not exist because of technological change or other developments. Functions traditionally performed by an operator may be unbundled (different entities provide different functions), distributed (no single entity has control over a given function), or both. While a number of organizational arrangements are possible in this environment, a distinguishing feature is that market outcomes are driven by end-user service providers. Although technological change may reduce 
the fixed costs of infrastructure in this environment, coordination among many providers may be costly, resulting in an ambiguous effect on overall costs. Easy market entry in this environment may intensify competition, which could result in lower fees and higher service quality. A decentralized environment without a central coordination body could face challenges. In the absence of such an entity, failure to coordinate on safety and security issues can increase vulnerability to cyberattacks, while the failure to coordinate on common rules or standards can exacerbate fragmentation.

Tools are available to promote positive outcomes in each market structure. Coordination on interoperability may help advance ubiquity and safety objectives but may also raise other issues, such as access pricing or settlement risk. Open, inclusive, and transparent governance arrangements can help payment stakeholders effectively make decisions on a variety of initiatives that can promote positive outcomes. In addition to private coordination arrangements, public authorities can play several important roles in protecting the public interest, such as regulator, supervisor, and catalyst for change.

Each of the three market structures examined has both advantages and disadvantages in meeting public policy goals. Moreover, their implications depend on more-detailed institutional features and other factors. Given the nascent state of the faster payments market and the tendency for path dependence in the payments industry, careful consideration of market structure implications is particularly relevant at this juncture. 


\section{Introduction}

The U.S. payments industry is in the midst of an effort to upgrade and improve payment capabilities for consumers and businesses. Over the last decade, the industry as a whole has adjusted slowly to the growing demands for greater convenience, speed, and safety in payments. Although various innovations have emerged in recent years, the reach and scope of new payment services have been limited, partially because of a lack of coordination in the industry. Recognizing this fact, the Federal Reserve published a consultation paper in 2013 that sought public input on ways to make broad enhancements to the U.S. payment system. ${ }^{3}$

After evaluating public comments and meeting with a diverse set of stakeholders, the Federal Reserve issued Strategies for Improving the U.S. Payment System (the SIPS paper) in 2015, which identifies a series of desired outcomes and strategies for improving the U.S. payment system. ${ }^{4}$ Among the desired outcomes is the provision of safe, ubiquitous, faster electronic solutions for making a wide variety of business and personal payments. Due to the efforts of the Faster Payments Task Force (FPTF) - a diverse array of stakeholders convened by the Federal Reserve as part of the SIPS initiative - and other efforts by industry participants, the payments industry is now working to develop and implement changes in the U.S. payment system to achieve these desired outcomes. In its final report, the FPTF set forth a roadmap for the industry to achieve its vision for faster payments by $2020 .^{5}$

As the industry turns to this next phase of efforts to improve the payment system, questions arise regarding the market structures that might support the provision of faster payments and the potential policy implications of those market structures. The SIPS paper anticipated such questions and stated that the Federal Reserve would "examine policy issues associated with a possible multi-provider environment, such as the framework for establishing rules." 6

This paper examines these questions and considers three hypothetical environments - or market structures - that may emerge in the long run in the faster payments market. The two initial scenarios involve operators, analogous to the traditional operators in legacy payment platforms, that consolidate a number of activities and serve a central role in the provision of

\footnotetext{
${ }^{3}$ Federal Reserve Banks (2013), Payment System Improvement - Public Consultation Paper, September 10, www.fedpaymentsimprovement.org/wp-content/uploads/2013/09/Payment System ImprovementPublic Consultation Paper.pdf.

${ }^{4}$ Federal Reserve System (2015), Strategies for Improving the U.S. Payment System, January 26, https://fedpaymentsimprovement.org/wp-content/uploads/strategies-improving-us-payment-system.pdf.

${ }^{5}$ Part two of the FPTF's final report calls upon payment stakeholders "to realize the vision for a payment system in the United States that is faster, ubiquitous, broadly inclusive, safe, highly secure, and efficient by 2020" and sets forth 10 recommendations for the industry to achieve this vision. See FPTF (2017), "Faster Payments Task Force Final Report Part Two: A Call to Action," July, http://fasterpaymentstaskforce.org/wp-content/uploads/fasterpayments-task-force-final-report-part-two.pdf.

${ }^{6}$ Federal Reserve System, SIPS paper, p. 3.
} 
faster payments. ${ }^{7}$ The first of these scenarios involves a single dominant operator, and the second involves multiple operators. Because technological changes have the potential to diminish the traditional operator role in the faster payments market, the third scenario considers an environment without a traditional operator.

Although recent market activity provides some indication of the number and types of firms that may enter the faster payments market in the short run, uncertainty still exists around how this market will evolve in the long term. The range of scenarios in this paper seeks to paint a broad picture of the possible policy issues associated with the potential market structure for faster payments, while acknowledging the uncertainties in this still emerging market. This paper does not predict or promote any particular market structure, nor does it make specific policy recommendations. Moreover, while some of the considerations may apply in the short term, the paper takes a longer-term view in its analysis of potential market outcomes.

The paper is organized as follows. Section 2 provides an overview of the various factors, including economic and institutional forces, that could influence the faster payment market's eventual structure. Section 3 examines the implications of different potential market structures, with a particular focus on efficiency, safety, and ubiquity. Section 4 discusses considerations for promoting outcomes in line with public policy objectives.

\footnotetext{
${ }^{7}$ The Committee on Payments and Market Infrastructures (CPMI) of the Bank for International Settlements (BIS) defines a "funds transfer system" as a "formal arrangement based on private contract or statute law, with multiple membership, common rules and standardized arrangements, for the settlement of money obligations arising between the members." In this paper, a "payment platform" is synonymous with this definition of a funds transfer system. CPMI (2016), "Glossary," www.bis.org/cpmi/publ/d00b.htm.

The BIS is an international organization owned by 60 member central banks from around the world. The CPMI, a standing committee of the BIS, promotes the safety and efficiency of payment, clearing, settlement and related arrangements by monitoring and analyzing developments in these arrangements, serving as a forum for central bank cooperation in related oversight, policy, and operational matters, and serving as a global standard setter.
} 


\section{Background}

At the heart of payments lies a fundamental coordination problem - the payer must have access to a payment method acceptable to the payee. More generally, a payment between end users requires a basic level of coordination on two fronts: an asset (or claim on an asset) to be transferred among those end users and a process that defines the procedures and obligations associated with that transfer.

Historically, governments helped to address this coordination problem through the provision of cash and the adoption of legal tender laws. Despite its wide acceptance and convenience for certain types of transactions, physical currency has limitations, particularly in efficiency and safety. Cash can be relatively costly to produce and use, in part because of the need for physical transfer, and lacks protections if lost or stolen.

Electronic payment platforms, like those for automated clearinghouse (ACH) and payment card transactions, each adopt different approaches to address the fundamental coordination problem while also ameliorating some limitations of cash. In the United States, these platforms have been provided by both the private and public sectors, to varying degrees. ACH platforms are operated by a private-sector firm and the Federal Reserve, while payment card platforms are operated solely by private-sector firms. In both cases, these platforms have helped foster coordination and agreement on a variety of issues, such as the type of access technologies employed and the specifications and processes for clearing and settlement. ${ }^{8}$ The institutional, technical, and legal arrangements that provide coordination and support these platforms play a critical role in payments, affecting their safety, speed, reliability, production costs (including the allocation of those costs among the parties involved), and other attributes.

As the U.S. payments industry seeks to develop new, faster payment methods, the fundamental coordination problem remains in focus, and the institutional arrangements that arise to address it will continue to play a critical role. As discussed in the Committee on Payments and Market Infrastructures (CPMI) report on fast payments, faster payment initiatives across the world largely seek to address two historical limitations of retail payment platforms: speed and service availability. ${ }^{9}$ Retail payments have traditionally taken at least a day for funds to reach the payee following initiation, and payment processing has often been limited to certain times of day.

\footnotetext{
${ }^{8}$ Other areas requiring agreement include issues regarding liability, compatibility, and security.

The CPMI defines clearing as "the process of transmitting, reconciling and, in some cases, confirming transactions prior to settlement, potentially including the netting of transactions and the establishment of final positions for settlement." The various processes involved in clearing generally require communication/messaging capabilities (for example, for transmitting transaction details between banks or other intermediaries). Settlement, which the CPMI defines as "the discharge of an obligation in accordance with the terms of the underlying contract," broadly involves the transfer of funds associated with a payment or group of payments. CPMI, "Glossary."

${ }^{9}$ CPMI (2016), Fast Payments - Enhancing the Speed and Availability of Retail Payments (Basel, Switzerland: Bank for International Settlements, November), https://www.bis.org/cpmi/publ/d154.pdf. Other common terms for these services are "fast," "instant," "immediate" or "real-time" payments.
} 
Accordingly, this paper uses the term "faster payment" to refer to a payment that provides near-instantaneous availability of final funds to the payee on a $24 \times 7 \times 365$ basis. This definition is advantageous in that it focuses on essential attributes of faster payments and is agnostic to implementation details, allowing for analysis in light of the breadth of institutional arrangements that may emerge in the in the U.S. faster payment market. As discussed throughout this paper, these arrangements may differ from those found in legacy payments markets.

This paper applies insights from the field of industrial organization to the market for faster payments in the United States. In the study of industrial organization, market structure refers to the institutional arrangements in a market. Key questions in this area relate to the number and type of firms and the nature of competition in a market, as well as the implications of these features for production and pricing.

Ownership structure, and how it relates to control over the production process, has important bearing on these questions. In many legacy payment platforms in the United States, a single institution or consortium of institutions owns and exercises control over many aspects of the end-to-end production process, a structure referred to as "vertically integrated." Payment card networks and $\mathrm{ACH}$ operators, for instance, provide many aspects of production, including clearing and settlement. In addition to providing these functions, payment card networks are also heavily involved in establishing and enforcing operating rules for card platforms. ${ }^{10}$ In contrast, rules governing ACH platforms are largely established by a separate entity. ${ }^{11}$ In light of evolving technology, future platforms could feature unbundled payment services, which may disperse more widely ownership and control over the various parts of production.

The fundamental coordination problem in payments, however, transcends the scope of conventional market structure analysis. In an attempt to address the other important institutional factors in the payments market, this paper considers rules and standards, as well as concepts like interoperability and governance arrangements. Additionally, this paper considers ways that public authorities may influence market outcomes. One source of uncertainty in the analysis is the nature of technological change and its implications for the market. This paper highlights the fact that emerging technologies may confound traditional assumptions in the payments industry and lead to market structures and institutions that deviate from historical norms.

\footnotetext{
${ }^{10}$ The term "rules" in this paper refers to the privately established rules of a payment platform unless otherwise specified. The term does not refer to laws or government regulations.

${ }^{11} \mathrm{ACH}$ transactions are governed in part by the operating rules and guidelines of NACHA - The Electronic Payments Association, a not-for-profit association. NACHA provides the legal foundation for the ACH Network through the development and enforcement of NACHA Operating Rules.
} 


\subsection{Economics of payment services}

Economic theory offers several concepts that help illuminate the factors that contribute to the emergence of different market structures, as well as the implications of those structures. These concepts - including economies of scale and scope, network effects, switching costs, and product differentiation - have significant influence on the payments market because they affect both the cost of payment processing on the production side and the demand for payment services on the consumption side. ${ }^{12}$

The discussion that follows generally focuses on economic forces relevant to operators of payment platforms, the institutions that have traditionally provided back-end infrastructure services like clearing and settlement. Some of these forces may also apply to payment service providers (PSPs), which this paper defines as the entities that provide front-end payment services and instruments to end users. ${ }^{13}$ Additional detail on how these forces may apply to PSPs is provided in footnotes when useful. Moreover, it is important to note that the following discussion may not apply cleanly to faster payments because the institutional arrangements that emerge in this market may differ from historical arrangements.

\subsubsection{Traditional economics of payment services}

Payment platforms tend to exhibit economies of scale and scope in production. Either of these effects can influence market structure by affecting the profitability of different arrangements for production and, hence, the feasibility of those arrangements for private suppliers of payment platforms. Both tend to limit the number of firms in a market, which may result in increased market power and profitability for those firms. ${ }^{14}$

Economies of scale occur in a production process where the average cost of producing a good or service falls as the quantity produced increases. Historically, payment platforms have exhibited economies of scale due to high fixed infrastructure and operating costs and low (and often decreasing) costs per additional customer or transaction. These infrastructure costs may have reflected capital investments in mainframe and telecommunication systems to provide messaging capabilities in order to reach a wide set of PSPs.

\footnotetext{
${ }^{12}$ See CPMI (2012), Innovations in Retail Payments (Basel, Switzerland: Bank for International Settlements, May), www.bis.org/cpmi/publ/d102.pdf.

${ }_{13}$ PSPs are often depository institutions or other intermediaries that interact through an operator of a payment platform; however, a single entity may play the roles of both operator and PSP. A situation in which a single PSP provides services only to its own customers is often referred to as a "closed-loop" payment platform. This scenario contrasts with an "open-loop" platform that connects many PSPs.

${ }^{14}$ See John C. Panzar (1989), "Technological Determinants of Firm and Industry Structure," in Richard Schmalensee and Robert Willig, eds., Handbook of Industrial Organization, vol. 1 (Amsterdam: Elsevier), pp. 3-59.
} 
In theory, scale economies may create a natural monopoly in which one player tends to have a large cost advantage that acts as a barrier to other entrants in the market. ${ }^{15}$ Importantly, the structure of costs, not the general existence of these costs, causes this outcome. Barriers to entry may be reduced if fixed costs are converted to variable costs. Such a conversion could result from technological innovations that alter the underlying production process. In such a case, new entrants may be able to operate with average costs similar to those of a large incumbent, which would then be subject to reasonable competitive constraints. ${ }^{16}$ If such changes were to occur in the payments market, the importance of large, central intermediaries in the production of certain payment types might correspondingly diminish.

Economies of scope occur in a production process where the average cost of producing several goods or services jointly is lower than producing each one independently. Payment platforms can exhibit economies of scope because the same infrastructure can be used to perform various stages of payment processing, such as clearing and settlement, or ancillary functions, such as directory services. ${ }^{17}$ In addition, the infrastructure used to process one payment type may be used to process other payment types or provide other services. ACH platforms in the United States, for example, process both debit-pull and credit-push transactions and provide messaging capabilities to transmit payment-related information. Moreover, an operator of an existing platform can capitalize on economies of scope by extending new payment services to its established base of end users, as when $\mathrm{ACH}$ platforms extended their existing next-day services to include same-day settlement capabilities. ${ }^{18}$

In addition to scale and scope economies, payment platforms exhibit network effects. One type of network effect, termed positive network externalities, arises when a good or service becomes more valuable as more users consume it. Payment platforms tend to exhibit direct positive network externalities: The value of a platform to an end user increases with the platform's ability to provide payments to a larger number of other users. A payment platform may also exhibit indirect positive network externalities: An increase in the platform's use enhances the value of complementary services, such as better software and additional payment functions (for example, bill-pay services), and these complementary services can, in turn, boost

\footnotetext{
${ }^{15}$ The OECD glossary of terms states that a "natural monopoly exists in a particular market if a single firm can serve that market at lower cost than any combination of two or more firms." See Organisation for Economic Cooperation and Development (2007), "Glossary of Statistical Terms," https://stats.oecd.org/glossary/download.asp. ${ }^{16}$ Even with such a shift in the cost structure, other economic effects such as network externalities may preserve barriers to entry.

${ }^{17}$ Economies of scope may also apply to PSPs because of their ability to bundle multiple payment services, as well as payment and other financial services, for end users.

18 This possibility may reflect economies of scope in production or economies of scope in consumption. The first concerns the cost of joint production relative to independent production. The second refers to a consumer's value of joint consumption. An example of the latter might be the convenience value of needing only one set of credentials to access several services if they are purchased from a single institution.
} 
use of the platform. ${ }^{19}$ Another type of network effect, termed two-sided market effects, relates to the composition of users of a good or service. In payments, two-sided market effects arise when two distinct groups of end users must participate in a platform for that platform to have value, and the value for one group depends on the size or composition of the other. ${ }^{20}$ For example, payment cards increase in value to consumers as more merchants accept them, and, conversely, merchants accept cards more readily the more consumers hold them. Similar to scale and scope economies, network effects can act as a barrier to entry.

Other important economic effects relevant for payments include switching costs and product differentiation. Both can have a limiting effect on competition in the payments market. End users incur switching costs when they abandon one platform (or service based on that platform) for another. ${ }^{21}$ Examples of these costs include the time and expense involved in registering with a new service, canceling arrangements with the existing one, and migrating scheduled payments to the new one. Product differentiation refers to firms offering products that differ from the end user's perspective. ${ }^{22}$ If end users differ in their preferences over product characteristics, they may not pick a product simply based on price. For example, some end users may value security over convenience, while others may have the opposite preference. Those focused on security may desire a service with two-factor authentication, but those focused on convenience may not. Differences in preferences make products less substitutable, reducing competitive pressures related to prices, and, as a result, create incentives for suppliers to differentiate. ${ }^{23}$

Historically, these economic forces have shaped a traditional role for an operator of a payment platform, as well as a role for PSPs, leading to market structures in legacy payment markets that feature a small number of large operators. In broad terms, an operator coordinates the provision of payments by PSPs to their end-user customers. Specifically, the traditional operator provides a payment platform that consolidates certain activities that allow banks or other PSPs to interact and execute payments on behalf of their customers. In this traditional role,

\footnotetext{
${ }^{19}$ See, for example, Michael L. Katz and Carl Shapiro (1985), "Network Externalities, Competition, and Compatibility," American Economic Review, vol. 75 (June), pp. 424-40.

${ }^{20}$ See, for example, Jean-Charles Rochet and Jean Tirole (2003), "Platform Competition in Two-sided Market," Journal of the European Economic Association, vol. 1 (June), pp. 990-1029.

${ }^{21}$ See, for example, Paul Klemperer (1995), "Competition When Consumers Have Switching Costs: An Overview with Applications to Industrial Organization, Macroeconomics, and International Trade," Review of Economic Studies, vol. 62 (October), pp. 515-39.

${ }^{22}$ See, for example, Avner Shaked and John Sutton (1987), "Product Differentiation and Industrial Structure," Journal of Industrial Economics, vol. 36 (December), pp. 131-46.

${ }^{23}$ In practice, switching costs and product differentiation can apply at different levels of a payment platform. For a closed-loop platform, these effects apply directly to the platform when it supplies services to end users. In an open-loop arrangement with multiple PSPs, these effects may influence end-user substitution across PSPs and, as a result, competition among them. Switching costs and product differentiation may also affect PSPs vis-à-vis a platform, as PSPs may incur costs to transition from one platform to another and may consider differences across platforms when PSPs make decisions about the platforms in which they participate.
} 
operators have historically capitalized on scope economies by providing, directly or through partners, many aspects of a payment platform, including payment and information processing, such as clearing and settlement, and the establishment of rules.

This organizational arrangement has often been less costly and otherwise more efficient for PSPs than less-centralized arrangements, given the high fixed costs historically associated with clearing. ${ }^{24}$ The importance of this traditional operator role is reflected in the fact that a consortium of depository institutions or other PSPs has often served as the creator of, and sometimes controls, a particular operator. Providing these functions in a vertically integrated fashion may afford operators a significant degree of control over the production process. ${ }^{25}$ While this control helps to address some coordination issues, it may also create challenges to competition in the payments market, such as market power related to pricing and standard setting. In turn, these challenges may preempt competitive entry, drive consolidation, and generate and preserve market power.

\subsubsection{Implications of technological change for the economics of payment services} Technological change may diminish the importance of some of these economic forces and enable alternate arrangements or business models that do not involve a traditional operator. ${ }^{26}$ Innovation may reduce economies of scale or scope in some aspects of the production process. For example, decreasing fixed costs for communications and computer processing may obviate the need for centralized message processing and computing resources. Similarly, distributed ledger technologies may reduce the cost or security advantages of operator-run directory and clearing services. Additionally, faster payments settled on a near-real-time (transaction-bytransaction) basis may remove the need for many traditional clearing functions, such as batch processing and multilateral netting.

These changes in technology may lead to institutional arrangements in the faster payments market that differ from those in legacy payments markets. To the extent that economies of scope become less relevant, new faster payment platforms could feature unbundled services, in

\footnotetext{
${ }^{24}$ Besides costs of production, costs associated with contracting or monitoring affect the relative efficiency of centralized versus decentralized arrangements. While these costs are broadly referred to as coordination costs in this paper, a number of researchers discuss them in more detail. Coase has explored different frictions and the relative efficiency of different methods of governing economic activity. Grossman and Hart have analyzed the costs of integrated versus arms-length relationships. See Ronald Coase (1937), "The Nature of the Firm," Economica, vol. 4 (November), pp. 386-405; Sanford Grossman and Oliver Hart (1986), "The Costs and Benefits of Ownership: A Theory of Vertical and Lateral Integration," Journal of Political Economy, vol. 94 (August), pp. 691-719.

${ }^{25}$ In practice, an operator may outsource various activities to third parties, such as payment processors. However, a traditional operator often maintains a significant degree of control over the actions of those parties through rules, pricing, or other methods.

${ }^{26}$ See, for example, David Mills, Kathy Wang, Brendan Malone, Anjana Ravi, Jeff Marquardt, Clinton Chen, Anton Badev, Timothy Brezinski, Linda Fahy, Kimberley Liao, Vanessa Kargenian, Max Ellithorpe, Wendy Ng, and Maria Baird (2016). "Distributed Ledger Technology in Payments, Clearing, and Settlement," Finance and Economics Discussion Series 2016-095 (Washington: Board of Governors of the Federal Reserve System), https://doi.org/10.17016/FEDS.2016.095.
} 
which different sets of entities provide different aspects of production. For example, for a given platform, one entity could provide settlement services, another clearing services, and yet another directory services. To the extent that technology reduces the importance of economies of scale, some services associated with a platform may be distributed, meaning that no single entity has control over the service. For example, a faster payment platform may allow PSPs to directly exchange clearing messages based on the platform's rules and standards without the need for an operator that provides centralized processing. These innovations could be naturally incorporated in the payment processing chain if private-sector providers face strong incentives to adopt them. In addition to private incentives, other factors, including industry-wide coordination efforts or actions by public authorities, may also influence the adoption of new technologies.

Although emerging and future technologies may support a variety of institutional arrangements in the payments industry, cost reductions for existing technologies, such as cloud computing, may also support less-traditional arrangements. The emerging organization of faster payments in certain jurisdictions, such as the European Union (EU) and Australia, in part reflects the adoption of existing technologies that support the unbundling of payment processing functions traditionally performed by an operator (see boxes 1 and 2). To varying degrees, the anticipated market structures in these jurisdictions reflect coordination between the private and public sectors. While the emerging faster payment markets in the EU and Australia are interesting to consider, it is important to reflect on the various ways these jurisdictions differ from the United States when examining them, such as differences in their regulatory environments or existing market structures.

Although certain economic forces may eliminate or reduce some of the conventional roles for an operator, other forces may continue to support those roles. Operators have historically served an important role as a central coordinating body, organizing the activities of end users and PSPs in a way that internalizes various externalities, including network externalities. This coordination role may persist even if operators are no longer necessary for traditional processing functions. Additionally, the effects of switching costs and product differentiation may remain at the PSP level, regardless of back-end arrangements of faster payment platforms. To the extent that certain roles of the traditional operator are eliminated or reduced, an important issue is whether the need for coordination and potentially some centralized activities, as well as forces like product differentiation and switching costs, continues to provide certain entities with market power. 


\section{Box 1: The layered approach to instant payments in the European Union}

As they develop and deploy faster payment capabilities, stakeholders in various jurisdictions are also considering market structure issues. The European initiative to develop "instant payment" solutions is a notable example. ${ }^{27}$ As in the United States, instant payments in the $\mathrm{EU}$ are complicated by the breadth of the payments landscape, the number and heterogeneity of the relevant parties, and the need for new arrangements and capabilities. The EU effort is particularly complicated by the need to preserve an integrated pan-European retail payments market, as achieved for credit transfers and direct debits through the Single Euro Payments Area (SEPA) initiative, and to avoid reintroducing fragmentation for instant payment solutions.

In late 2014, the Euro Retail Payments Board (ERPB) called for at least one instant payment solution to be available to every PSP in Europe, through either pan-European solutions or interoperable national solutions. ${ }^{28}$ To achieve this goal, the ERPB advised the industry not to adopt a "siloed" approach with noninteroperable solutions, but to develop solutions based on a "layered" approach. Specifically, the ERPB identified three primary layers: the scheme layer, which concerns instant payment rules and standards; the clearing layer, which broadly involves how PSPs exchange payment information; and the settlement layer, which addresses how PSPs settle instant payments. The ERPB envisions that this approach could avoid fragmented instant payment solutions and could instead facilitate interoperability consistent with both the ERPB's vision and the broader SEPA objectives.

More broadly, this approach yields a somewhat different role for operators in the instant payments market. Whereas a traditional operator would provide (or establish arrangements for) the scheme, clearing, and settlement functions, the layered approach separates these functions such that multiple parties can provide certain elements in either a cooperative or a competitive fashion. European authorities envision that competition will mainly occur on a fourth layer associated with end-user solutions, rather than on the more foundational scheme, clearing, or settlement layers.

Progress has been made on all three layers in Europe. For the scheme layer, in late 2016, the European Payments Council (EPC) published a SEPA Instant Credit Transfers (or SCT ${ }^{\text {inst }}$ ) rulebook for voluntary adoption by PSPs in late 2017. ${ }^{29}$ For the clearing layer, the ECB has presented expectations for clearing infrastructures on how to achieve interoperability. For the settlement layer, the ECB plans to provide dedicated technical accounts that will jointly hold the funds of participants in a particular clearinghouse. These technical accounts can be used to effect $24 \times 7 \times 365$ real-time settlement among the clearinghouse's participants, backed by funds at the central bank. ${ }^{30}$ Furthermore, in mid-2017, the ECB began developing the TARGET Instant Payments Settlement (or TIPS) service, which will provide a 24x7×365 real-time transaction-by-transaction settlement service for instant payments using accounts of individual PSPs at the central bank. Set to commence in 2018 , this service is intended to complement other settlement services for instant payments and contribute to pan-European reachability while mitigating credit risk.

\footnotetext{
${ }^{27}$ See European Central Bank (ECB), "Instant Payments," www.ecb.europa.eu/paym/retpaym/instant/html/index.en.html.

${ }^{28}$ The ERPB is chaired by a representative from the ECB and is composed of seven representatives from the supply side of the market (such as banks and payment institutions) and seven representatives from demand side (such as consumers and retailers). In addition, five national Eurosystem central banks and one non-Eurosystem central bank participate in the ERPB on a rotating basis.

${ }^{29}$ The EPC is an association of PSPs in the EU that looks to harmonize payments in SEPA. To do so, the EPC manages payment schemes associated with various payment types, including instant credit transfers.

${ }^{30}$ These accounts involve an arrangement called TARGET2 Ancillary System Interface procedure 6 real time (or ASI6 real time). These accounts will be available to TARGET2 participants.
} 


\subsection{Faster payments landscape}

In the United States, efforts to launch faster payment platforms are shifting from the design and assessment stage to the implementation stage. Some private-sector entities have implemented or are currently implementing faster payment platforms, while others have expressed an intent to enter the market. Despite these short-term developments, it is still uncertain how the U.S. faster payments market will develop in the long run. A number of important questions remain.

How many faster payment platforms will survive in the long run? What types of institutional arrangements will emerge to support those platforms? How will the market share be distributed across them? Though these questions are difficult to answer at this stage, the economic concepts discussed in section 2.1 and recent market developments provide some indication of the range of long-run possibilities in the U.S. market. Before turning to these possibilities, this subsection discusses faster payment implementations in other countries.

\subsubsection{International landscape}

Globally, a number of countries have already implemented faster payment services, and several other countries and jurisdictions are currently in the development stage. ${ }^{31}$ Almost all of those countries have or will have only a single platform for faster payments. Generally these platforms are supported by traditional institutional arrangements. A single operator typically owns and operates these platforms and the associated infrastructure services, such as clearing and settlement services. In most of these countries, a clearinghouse or a consortium of private banks play this role. In some countries, the central bank provides various operator services for faster payments. For example, in Mexico and China, the central bank serves as the operator providing clearing and settlement services.

The initiatives to provide faster payments in the EU and Australia differ notably from the common single-operator arrangement. In broad terms, these initiatives envision arrangements that unbundle the different functions of a faster payment platform such that they are not provided by a single operator, though certain functions are still largely provided by one or more central intermediaries (see boxes 1 and 2). In the EU, a real-time, transaction-by-transaction settlement service will be provided by the central bank, possibly eliminating parts of the clearing function for faster payments. In Australia, clearing and settlement will be unbundled, but each will be provided by a single entity. Both initiatives provide PSPs access to the payment infrastructure in a way that is intended to encourage competition in front-end payment services.

\footnotetext{
${ }^{31}$ The CPMI report on fast payments catalogs some of these developments. See Annex 2 of CPMI, Fast Payments, p. 74.
} 
Box 2: Australia's New Payments Platform

In 2012, the Reserve Bank of Australia (RBA) published the RBA's Payments System Board's conclusions from its Strategic Review of Innovation in the Payments System. ${ }^{32}$ The conclusions laid out an initial set of strategic objectives for innovation, including the ability to make and receive real-time retail payments, and the industry was invited to determine the most effective way of delivering on those objectives.

In response, an industry committee proposed the development of a new, purpose-built, open-access infrastructure, called the New Payments Platform (NPP), for fast payments in Australia. As part of its proposal, the industry committee determined that a layered approach would appropriately balance the desire to maximize economies of scale and network effects against the desire to encourage innovation and competition in the provision of payment offerings. The layered approach in Australia differs from that of the EU (see box 1), with Australia focusing on building a utility at the basic level of infrastructure (clearing and settlement), which, along with other policies, should encourage competition for additional fast payment services tailored to meet the evolving needs of end users.

The design of the NPP will consist of

(i) A basic infrastructure - a central underlying infrastructure being built by SWIFT that will connect participating institutions and allow payment and settlement messages to flow between them.

(ii) Overlay services - the basic infrastructure will support various tailored commercial payment services that participants can choose to make available to their customers. The intent is to allow for multiple overlay services to develop over time. The first overlay service, the Initial Convenience Service, is expected to launch at the same time as the NPP. The Initial Convenience Service will enable Authorised Deposit-taking Institutions (ADIs) to provide their customers with the ability to make P2P mobile, tablet, or internet payments with near-real-time funds availability to any customer of another participating ADI.

(iii) A fast settlement service - a settlement component being built by the RBA to allow for individual, real-time settlement of NPP payments.

The initial industry proposal set out a number of key advantages to the layered approach of separating a basic infrastructure from overlay commercial services. First, the operational priorities of the basic infrastructure will center on the common needs of its members, including efficient service and resiliency. Second, the layered approach has the potential to change the competitive dynamics in the payments market: the basic infrastructure is designed to maximize economies of scale, while the overlay services allow innovation in payment services to meet the different needs of distinct user groups. Third, excluding commercial services from the basic infrastructure decreases the risk and complexity of its design and implementation. Fourth, open access of the basic infrastructure should help drive universal participation by ADIs.

The layered approach, while providing for competition on a range of aspects such as timing needs, data richness, and pricing, nonetheless requires consideration of issues related to interoperability. For example, participation requirements and rules regarding turnaround times for messaging will still be necessary to enable all ADI participants to deliver the basic functionality of real-time payments. Effective governance of the system is also paramount, with NPP Australia Limited being formed to oversee the build, operation, and management of the NPP, including establishing rules for the basic infrastructure and providing access in a way that encourages competition in payment services. The NPP is expected to launch in late 2017.

\footnotetext{
${ }^{32}$ Reserve Bank of Australia (2012), Strategic Review of Innovation in the Payments System: Conclusions, June, www.rba.gov.au/payments-and-infrastructure/payments-system-regulation/past-regulatory-reviews/strategicreview-of-innovation-in-the-payments-system/conclusions/pdf/conclusions-062012.pdf.
} 


\subsubsection{United States landscape}

Although the experience of other countries provides a useful benchmark for comparison, the market for faster payments in the United States is expected to differ in certain respects. In many countries, the common single-platform outcome reflects mandates or other actions taken by the public sector or central banks to influence that outcome. In contrast, the United States has taken to date a market-based approach to implementing faster payments.

As outlined in the SIPS paper, the Federal Reserve has taken a leadership role to catalyze market-based solutions that are aligned with the public interest. In 2015, the Federal Reserve assembled the FPTF to collaboratively identify and assess potential approaches for implementing faster payments. In January 2016, the FPTF published a set of Effectiveness Criteria describing attributes and expectations of effective faster payments solutions in terms of six categories: ubiquity, efficiency, safety and security, speed, legal, and governance. ${ }^{33}$ In addition, the FPTF invited its members to submit proposals for faster payment solutions through a process that involved assessment against the Effectiveness Criteria. Ultimately, 16 proposers completed the entire assessment process. Whether these proposals are ultimately implemented in the market will depend on actions taken by the private sector. As discussed in part two of the FPTF final report, the proposals are currently in different stages of development: some are conceptual in nature, while others are under development or already available in the market. ${ }^{34}$ In addition to the FPTF proposals, a few private-sector entities have launched or expressed the intent to launch faster payments platforms. ${ }^{35}$

In light of the market-based approach in the United States, the faster payments market may develop along a number of conceivable paths. The FPTF proposals and other recent market activity indicate that multiple faster payment platforms may emerge in the short run; however, the long-run equilibrium is less clear. In part, prediction is difficult because of the complexity of the U.S. payments market, which comprises a diverse set of financial institutions, technology providers, end users, and other stakeholders. A fundamental uncertainty is whether the evolving technological landscape will disrupt traditional economic forces in the payments market.

If traditional economic forces hold, the faster payments market may evolve in a way that continues to favor traditional business models and market structures. As discussed in section 2.1 , these forces tend to yield large operators that provide many traditional aspects of production. These forces also tend to drive platform consolidation in the long run because, under scale and scope economies, small operators may not be able to achieve the cost

\footnotetext{
${ }^{33}$ FPTF (2016), “Faster Payments Effectiveness Criteria," January 26, https://fedpaymentsimprovement.org/wpcontent/uploads/fptf-payment-criteria.pdf.

${ }^{34}$ See FPTF, "Final Report Part Two," p. 13.

35 To avoid any appearance of endorsing a private-sector entity or arrangement in the still emerging U.S. faster payments market, this paper does not discuss specific faster payment platforms or proposals.
} 
efficiencies necessary to be

profitable in the long run. As

discussed in box 3 , significant

consolidation occurred in the $\mathrm{ACH}$

market over the course of several decades. ${ }^{36}$ To the extent that the faster payments market involves similar economic forces and, as a result, evolves in a similar way, one may expect to see a few large operators or possibly a single dominant operator.
Box 3: Evolution of ACH platforms in the United States In the three decades that followed the launch of the nation's first ACH platform in 1972, several regional ACH platforms emerged and subsequently closed or consolidated. The consolidation that occurred is consistent with changes in computer and telecommunication technologies during this period, which may have conferred cost advantages to centralized payment processing. By the early 2000 s, four operators remained in the market: the Federal Reserve, The Clearinghouse (TCH), VISA, and Arizona Clearinghouse Association (ACHA). By 2003, VISA and ACHA had left the market, and since then the Federal Reserve and TCH have remained the only two operators in the market, highlighting the importance of economies of scale.

Alternatively, if new emerging technologies alter traditional economic forces, new business models and market structures may emerge in the faster payments market in the long run. Of the FPTF proposals that completed the assessment process, several envision employing emerging technologies, such as distributed ledgers and digital currencies. As discussed in the economics section of this paper, these and other developments in technology may alter the way payments are processed and lead to the formation of new types of intermediaries in the payments process or changes to the roles of existing intermediaries. Although it is difficult to foresee how the institutional arrangements in faster payments may shift, it is possible that some functions performed by a traditional operator would be unbundled, distributed, or both. In such a scenario, PSPs would likely continue to play an important role in providing payment services to end users; however, the degree to which intermediaries play a significant role in facilitating interaction among PSPs would depend on the specific technological and institutional arrangements that emerge.

These observations suggest that a range of market structures may emerge over the long run in the U.S. faster payments market. The next section provides an analysis of a few hypothetical market structure models that are intended to broadly reflect this range.

\footnotetext{
${ }^{36}$ Significant consolidation also occurred in the ATM and debit card markets. See Fumiko Hayashi, Richard Sullivan, and Stuart E. Weiner (2003), A Guide to the ATM and Debit Card Industry (Kansas City, MO: Payments System Research Dept., Federal Reserve Bank of Kansas City), https://www.kansascityfed.org//publicat/psr/bksjournarticles/atmpaper.pdf.
} 


\section{Market structure implications}

Efficiency, safety, and ubiquity are fundamental public policy objectives in the faster payments market. Efficiency measures the social benefit of faster payments services against the end-toend social cost of providing such services. Safety refers to the reliability and integrity of faster payment platforms and includes effective risk-management and end-user protections. Ubiquity refers to the ability of end users to seamlessly exchange faster payments with any other end user in a variety of circumstances and reflects the wide adoption and use of faster payments by end users.

The market structure for faster payments will have significant implications for these public policy objectives. Market structure broadly encompasses the number and type of firms in a market, as well as the nature of competition among those firms. Economic forces will not only help shape the market structure for faster payments, but will also interact with the market's eventual structure to influence outcomes. These outcomes will depend in part on the degree and allocation of market power among participants, which in turn may depend on factors such as available substitutes or ease of market entry.

In the discussion below, three market structure models are analyzed, with a particular focus on efficiency, safety, and ubiquity. The first two models - the dominant-operator environment and the multi-operator environment - assume the traditional role of the operator is largely preserved in the faster payments market. In these environments, faster payment operators are generally large, vertically integrated firms providing many traditional functions of an operator in legacy payment markets (for example, clearing, settlement, and rulemaking). The third model - the decentralized environment - assumes that the roles of operators and other intermediaries in the faster payments market deviate from those in legacy payment markets. This model is motivated by ongoing technological developments that have the potential to disrupt traditional institutional arrangements in the provision of payment services.

It is worth noting that economic forces and the nature of competition may shift as the faster payments market evolves. Shifts in the market structure may occur due to platform consolidation or technological developments. Even if the initial market structure persists in the long run, economic incentives and other forces may shift in ways that change market outcomes. For example, a dominant operator's profit maximizing strategy may involve setting low fees initially to grow its network, followed by higher fees in the long run once the network is established. To simplify the discussion, the following subsections focus on long-run economic forces and outcomes in each environment.

\subsection{Dominant-operator environment}

In the dominant-operator environment, a single dominant operator has captured the vast majority of the market share. This dominant operator may be the sole player in the market or may coexist with smaller operators running distinct platforms, each with insignificant market share relative to the dominant operator. 
Importantly, a dominant operator may or may not have market power. A dominant operator may not have demonstrable market power if faster payments and other payment methods, like $\mathrm{ACH}$ and payment cards, are close substitutes, and the operator needs to compete against providers in those other markets. ${ }^{37}$ Further, market power may be limited if the dominant operator believes that potential competitors may enter the faster payments market.

Alternatively, a dominant operator may have market power if substitutability between faster payments and legacy payments is limited. Even if a close substitute exists, the dominant operator may have market power if it is also a dominant provider of that substitute. ${ }^{38}$ This subsection focuses on the case where the dominant operator possesses some market power, unless specifically mentioned otherwise.

\subsubsection{Efficiency}

Because of economies of scale and scope, a dominant operator may result in efficient production because replicated fixed costs associated with multiple platforms are avoided. Regardless of whether it has market power, a dominant operator may achieve the lowest resource cost incurred by society as a whole and the lowest average cost per transaction.

A dominant-operator environment also may achieve lower coordination costs than the multioperator and decentralized environments. There may be less need for coordination on initiatives like interoperability between payment platforms. Additionally, a market with a dominant operator may reduce the need for PSPs or other third parties to build multiple versions of front-end products to ensure compatibility with multiple platforms.

Despite these cost efficiencies, a lack of competitive discipline may lead a dominant operator to set a fee structure that results in suboptimal adoption or utilization of its platform. On the one hand, a lack of competition may induce a dominant operator to set a common, high fee across customers, discouraging adoption and utilization - the standard deadweight loss of monopoly. ${ }^{39}$ On the other hand, instead of setting a common price, a dominant operator may have the ability to price discriminate based on the price elasticity of demand of different

\footnotetext{
${ }^{37}$ The extent to which legacy payment methods serve as a close substitute for faster payments may vary by use case. For example, payment cards and faster payments could be close substitutes for consumer-to-business use cases but not for a large-value business-to-business use case.

${ }^{38}$ Legacy operators, able to capitalize on their current client bases and subsidize new products from their current business, may have significant market power, especially at early stages in the development of the market for faster payments. In addition to using old business lines to capture new markets, legacy operators might have incentives to deter entry of socially desirable faster payment platforms in order to preserve older profit centers. This might involve price discrimination, bundling, cream skimming (the selective targeting of the most profitable use cases with the intention of blocking entry of other providers), or other tactics that could have negative implications for end-users. For a description of such issues in a different industry, see Mark Armstrong and John Vickers (1996), "Competition and Regulation in Telecommunications" in George Yarrow and Piotr Jasinski, eds., Privatization: Critical Perspectives on the World Economy, vol. 2 (London: Routledge), pp. 180-203.

${ }^{39}$ In a closed-loop platform, the operator directly charges fees to its end users. In an open-loop platform, the operator charges fees to the PSPs, and in turn, the PSPs charge fees to their end-user customers.
} 
groups, allowing the operator to set higher prices to those who are willing to pay more. ${ }^{40}$ Relative to setting a common price, price discrimination may encourage higher adoption and utilization of faster payments. Nevertheless, it is only in limited circumstances that price discrimination results in socially optimal levels of adoption or usage. ${ }^{41}$ Even when price discrimination brings adoption or usage to a more socially optimal level, it may lead to crosssubsidization for different groups of end users, which may be perceived as inequitable.

In addition, although this analysis focuses on the operator itself, the outcomes for end users depend on competition among PSPs, and a dominant operator may influence that competition. The fees, rules, and standards that a dominant operator sets in the market will affect the costs of PSPs that use its platform. This effect on costs will, in turn, influence the outcome of competition among PSPs for end users. Moreover, if the operator prioritizes commercial interests of certain PSPs over those of other PSPs, because of either its ownership structure or its desire to attract more profitable customers, then its fees, rules, and standards may provide competitive advantages to the operator's preferred PSPs. Such imbalances may negatively affect outcomes for end user customers of the remaining PSPs.

Innovation is another important aspect affecting efficiency. A dominant-operator environment may exhibit both positive and negative effects on innovation, making the net effect unclear. Because a dominant operator's platform serves the vast majority of the market, it may be cheaper for PSPs and other third parties to develop and implement innovative services building on that platform. In addition, a dominant operator itself may have a strong incentive to innovate: If the dominant operator has market power, it has the ability to reap the benefits from its investment in innovation. In a more competitive environment, investments in innovation may not be recouped if the innovative offering can be quickly imitated. This concern is not present in the dominant-operator environment. On the other hand, a dominant operator may not face competitive pressure to innovate and may choose to rely on existing technology, leading to less innovation and lower quality products.

\subsubsection{Safety}

In many respects, a dominant operator may be able to address security issues quickly and efficiently due to its size and influence over the market. The security of faster payments requires efforts by all participants - not only operators and PSPs, but also other entities in the supply chain, as well as end users. Coordination among these participants on safety issues may be less costly in a dominant-operator environment. For example, a dominant operator that requires its customers to adopt certain security technologies or protocols would likely cover the vast majority of the faster payments market. Additionally, given its relative size in the market, a

\footnotetext{
40 This pricing is so-called "Ramsey pricing." See Jean-Jacques Laffont and Jean Tirole (1999), Competition in Telecommunications (Cambridge: MIT Press).

${ }^{41}$ See, for example, Zhu Wang and Julian Wright (2017), "Ad Valorem Platform Fees, Indirect Taxes, and Efficient Price Discrimination," RAND Journal of Economics, vol. 48 (Summer), pp. 467-84.
} 
dominant operator would generally have broad access to information on fraud and risks, which may position it to quickly and effectively identify and respond to threats. A dominant operator may also have significant incentives to maintain the safety of its platform. Relative to smaller operators, a dominant operator may be subject to a higher degree of reputational risk, as well as a higher direct effect on its profitability, given that an incident affecting its platform could have wide-reaching effects on the overall market. The costs associated with a reputational risk, however, may be limited in the absence of available substitutes or in the presence of high switching costs.

In other respects, a dominant operator's size and influence over the market may present challenges related to safety. A lack of competitive pressure may lead to lower quality products, which could include weaker security features or reduced end-user protections in the event of a loss. ${ }^{42}$ Moreover, a dominant operator represents a large single point of failure (or point of attack for bad actors) and, as a result, may concentrate operational, settlement, or other risk. If a dominant operator does not have sufficient redundancy arrangements, the faster payments market may exhibit inadequate business contingency in the event of an operational incident or during the times of crisis.

\subsubsection{Ubiquity}

In a dominant-operator environment, market fragmentation - a situation in which multiple platforms provide services to different sets of customers - would not be a major concern because the dominant operator serves the vast majority of the market. As a result, a dominant operator may be able to achieve ubiquity more easily than providers in other environments.

However, a lack of competitive pressure may negatively affect ubiquity. Market power of a dominant operator may lead to high fees, which may reduce end-user adoption of faster payments. Moreover, the lack of competitive discipline on a dominant operator may lead to lower quality products, which further stunts adoption. ${ }^{43}$

It is less clear whether a dominant-operator environment has an advantage or disadvantage in offering faster payments services to less profitable end-user segments, such as unbanked and underbanked segments, or hard-to-address use cases, such as cross-border payments. On the one hand, a dominant operator may be reluctant to serve these segments due to a lack of competitive pressure. On the other hand, a dominant operator may have incentives to use more profitable end-user segments to cross subsidize less profitable end-user segments or hard-to-address use cases.

\footnotetext{
42 To the extent that consumer protection laws limit end user liability, competitive pressure may or may not lead to protections beyond those required by law. This is just one example of an area where public authorities may play an important role, as discussed in section 4.4 .

${ }^{43}$ High fees and low quality may also influence PSP decisions about whether to participate in a dominant operator's platform, thereby affecting ubiquity through the services that they offer to end users.
} 


\subsection{Multi-operator environment}

In the multi-operator environment, multiple operators with significant market shares coexist, but none has captured the vast majority of the market. ${ }^{44}$ Compared with a dominant-operator environment, a multi-operator environment exhibits several features - including competitive pressures, replication of fixed costs, and potential product differentiation - that affect the public policy goals of efficiency, safety, and ubiquity.

\subsubsection{Efficiency}

A fundamental issue concerns cost efficiencies with multi-firm production. Multiple operators may replicate large fixed costs of infrastructure development, such as end-user access points, messaging and directory standards and systems, and security measures. Replicating these investments may have a high social cost, undermining efficiency.

A multi-operator environment may help alleviate market power concerns in a dominantoperator environment. In particular, competitive pressures between multiple operators may result in lower total fees to end users, higher quality products, and a greater variety of products addressing different use cases. All of these outcomes are typically associated with enhanced efficiency.

However, a number of features may limit or counteract the effectiveness of competition and the resulting efficiency gains in a multi-operator environment. Product differentiation is one potential source of market power even in a market with multiple operators. Although product differentiation may reflect improved quality or services tailored to the needs of certain end users or use cases, it may also allow firms to decrease the sensitivity of demand to price and, thus, to soften competition. Switching costs are another potential source of market power. These costs reduce competitive pressure by preventing PSPs or end users from selecting platforms that offer marginal improvements in price or quality. Both product differentiation and switching costs may impede competitive forces to lower fees, thereby affecting efficiency.

Network effects reflecting the two-sided nature of many payments markets may also lead to counterintuitive outcomes of competition. Adoption patterns across groups of end users may affect competition. If one group of end users (for example, consumers) adopts a limited number of services, while another (for example, merchants) adopts a wide range of services, then competition among operators may be focused on the end user group adopting a limited number of services. Operators may look to attract those end users with funds raised through higher fees on the group with wide adoption. In addition to having distributional consequences, such skewed pricing may result in higher total fees, which may reduce efficiency. ${ }^{45}$

\footnotetext{
${ }^{44}$ At least two operators in this environment have significant market shares. In the United States, a multi-operator environment exists for many types of legacy payments, including $\mathrm{ACH}$ and payment card transactions.

${ }^{45}$ See, for example, Graeme Guthrie and Julian Wright (2007), "Competing Payment Schemes," Journal of Industrial Economics, vol. 55 (March), pp. 37-67.
} 


\subsubsection{Safety}

Certain features of a multi-operator environment may enhance safety. Multiple operators may enhance resiliency if, in the event of an outage or disruption to one operator, other operators can effect payments that would otherwise have been prevented or delayed. In addition, competition may generate improvements in fraud prevention and data security, if competing operators find such improvements necessary to attract PSPs or end users.

Notwithstanding these positive effects, competitive forces may not result in a product mix that enhances safety. End user preferences and behavior related to the safety of payment methods may affect the safety features of the product mix offered by suppliers. If end users value convenience over security, an operator may choose not to introduce a new, cost-effective security method that is inconvenient for an end user, preferring to avoid the risk of losing customers to another operator that does not adopt the method. Some balance between safety and convenience is necessary in any payment arrangement. ${ }^{46}$ However, if competitive pressures skew more towards convenience, this dynamic may conflict with security goals. This possibility may be particularly pronounced if competing operators fail to account for the effect of their safety features on other operators or fail to induce customers to internalize the effects of their security choices on other end users. Coordination across operators may alleviate the first concern with, for example, agreement on security standards encouraging industry-wide upgrades. Similarly, an individual operator can coordinate security across its end users and may have incentives to do so. Nevertheless, there may be costs of coordinating precautions both across and within operators.

\subsubsection{Ubiquity}

Certain forces may foster or impede ubiquity in a multi-operator environment. The competitive forces that can promote efficiency may also serve to enhance ubiquity because efficient outcomes, such as lower fees and higher quality products, tend to increase end-user adoption. However, the features that can limit competition, such as product differentiation or switching costs, and the potential for skewed pricing due to two-sided market effects may yield prices and products that do not generate widespread adoption.

A particular challenge for achieving ubiquity in a multi-operator environment is fragmentation, a situation in which multiple platforms provide services to different sets of customers. If the platforms are not interoperable (that is, they do not communicate with each other), either end users would need to enroll in multiple platforms or PSPs would need to participate in multiple platforms to enable their end-user customers to exchange payments with a wide range of other end users. If neither of these occur because of cost or inconvenience (for example, if multiple access devices are required), fragmentation would prevent some users from exchanging

\footnotetext{
${ }^{46}$ See, for example, Allen N. Berger, Diana Hancock and Jeffrey C. Marquardt (1996), "A Framework for Analyzing Efficiency, Risks, Costs, and Innovations in the Payments System," Journal of Money, Credit and Banking, vol. 28 (November), pp. 696-732.
} 
payments or from adopting faster payments due to diminished positive network externalities, thereby preventing ubiquity.

\subsection{Decentralized environment}

Sections 3.1 and 3.2 assumed environments involving operators, emphasizing competition and coordination issues among entities that serve in that traditional role. This section considers an environment where technology or other developments diminish the importance of those entities and competition on that level. In the decentralized environment, PSPs play a pivotal role in determining outcomes for key public policy objectives. ${ }^{47}$

A range of institutional arrangements are possible in this environment; this analysis is not intended to predict how evolving technologies may influence the development of the faster payments market. In general terms, the analysis envisions that there exist substitutes for the various services traditionally bundled together by operators, such as clearing and settlement. Some of these services may be provided through widely available, low-cost facilities or technologies, which may or may not be controlled by a central intermediary. For example,

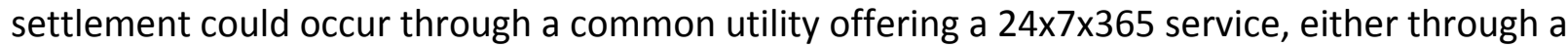
central facility or a utility based on a distributed ledger technology, and clearing messages could be exchanged bilaterally in a secure form on the open Internet. Some traditional operator services may simply be obsolete. For example, if payments are settled in real time on a transaction-by-transaction basis, the need for multilateral netting and other activities associated with centralized clearing would be reduced. Similarly, centralized computing facilities (or dedicated server-based systems) can, to some extent, already be replicated with on-demand cloud computing services. Regardless of the exact arrangement, a traditional operator that integrates many aspects of payment production would not exist in this environment, although PSPs would continue to provide services to end users.

\subsubsection{Efficiency}

In this environment, firms may not face high fixed costs of centralized infrastructure. The absence of fixed infrastructure costs that traditionally lead to central operators, however, would not necessarily imply a less costly faster payment platform. In the absence of a traditional operator, payments still require the exchange of information. PSPs that wish to exchange payments would need to adopt alternative arrangements to coordinate with each

\footnotetext{
${ }^{47}$ In principle, this analysis could be extended to a fully decentralized environment in which PSPs also cease to play a role and end users effectively engage in peer-to-peer exchange of payments. Digital currencies combined with a distributed-ledger technology and an underlying protocol for transactions serve as a potential example. Among other things, the removal of frictions (and market power) associated with intermediaries is often cited as a benefit of this arrangement. However, as Mills and others point out in their analysis of distributed-ledger technology, a fully decentralized environment would face extreme coordination difficulties. In addition, the continued existence of depository institutions and other PSPs is likely for a number of reasons, such as economies of scale at the PSP level and economies of scope in the ability to bundle payment services and other financial services. While a fully decentralized environment raises interesting issues, the current analysis focuses on the more likely scenario where PSPs continue to play an important role. See Mills and others, "Distributed Ledger Technologies," p. 27.
} 
other. These arrangements, which would depend on various factors, including technological developments, could include bilateral messaging, distributed ledgers, or other protocols. Although these arrangements may not be inherently more costly, they may replicate costs, such as the costs of maintaining databases or directories. These replicated costs could be avoided through some other mechanism for coordination among PSPs, but coordination itself may involve costs that could be avoided with a central operator. As a result, the overall implications for costs in a decentralized environment appear ambiguous.

The decentralized environment may enhance competition in several ways. When considering these positive effects, it is important to note that the decentralized environment, by removing the operator, focuses competitive considerations on competition among PSPs. While PSP competition is important in any environment, competition at the PSP level is the primary concern in the decentralized environment. ${ }^{48}$ Considering only depository institution PSPs, the existing market structure for financial services in the United States would yield a large number of PSPs in this scenario with fairly diffuse market shares, suggesting a potentially high level of competition among them. In addition, entry may be relatively easy, reflecting the assumption that the underlying technologies or services for conducting faster payments are widely available to PSPs. This increased entry may enhance competition. Most fundamentally, the absence of a central operator in this scenario implies that competition among PSPs would not be influenced by such an operator's terms, rules, and fees. Because of the lack of a traditional operator and the resulting direct competition between a potentially large number of PSPs, the decentralized environment could generate a situation in which PSPs would fluidly and intensely compete for end user business given the underlying platform, with the result being lower fees for end users and higher quality products.

At the same time, the competitive benefits of the decentralized environment may be limited. With competition occurring between PSPs in a decentralized environment, PSPs may individually possess some market power. In particular, product differentiation and switching costs may convey some market power to individual PSPs. Moreover, because PSPs would still need to coordinate to conduct payments, coordination costs may limit the extent of entry and, as a result, the competitive effects of entry. Finally, to coordinate payments among disparate PSPs, certain centralized activities would still be necessary in this environment, even if those activities are not associated with a traditional operator. ${ }^{49}$ These centralized activities may include rules, standards, directory services, or settlement facilities. Whether market power remains in the activities that still require coordination will depend in part on the mechanisms employed to provide these activities.

\footnotetext{
${ }^{48}$ Conceptually, the decentralized scenario involves an extension of the previous scenarios to a situation where many entities, as opposed to one (dominant operator) or a small number (multi-operator), are relevant for the provision of faster payments.

${ }^{49}$ For example, even fully decentralized environments, such as those associated with certain digital currencies, require coordination on protocols to conduct transactions.
} 
The decentralized environment may have similarly mixed effects on innovation. On the one hand, this environment may provide more flexibility and scope for innovation if PSPs are able to adapt underlying technologies to provide improved services to end users. The more-direct competition between PSPs may engender these innovations. For example, the potential of "value-added" services may be a particularly important aspect of a decentralized environment. On the other hand, if innovators are unable to recoup their investment costs, they may be unwilling to make those investments. As a result, the effects of the decentralized environment on innovation may depend on whether individual PSPs can experience sufficient benefits to offset their investment costs.

\subsubsection{Safety}

The decentralized environment may have certain safety advantages over an environment with a traditional centralized operator. By distributing certain payment functions, decentralization may reduce concentration of operational risk and provide opportunities for enhanced resiliency. For example, distributed and flexible computing and communication functions may reduce the risk of an outage because of a failure of centralized back-end infrastructure. However, if certain functions continue to be centralized in this environment (for example, in a centralized settlement utility), those functions may continue to serve as a central point of failure that requires very high degrees of resilience. In addition, depending on how it is structured, a decentralized environment may introduce more potential points of vulnerability to events such as cyberattacks and hacking.

The security of a decentralized environment, for both end users and the overall platform, will heavily depend on individual PSPs' underlying incentives and resulting decisions related to their security measures and risk mitigants. On the one hand, competition among PSPs may lead to enhanced security as PSPs compete for end users through more-secure service offerings. On the other hand, as in the multi-operator environment, competition may not necessarily yield greater security if it causes PSPs to instead focus on potentially conflicting attributes, such as convenience.

In the decentralized environment, these difficulties can be exacerbated by the lack of an operator or other central entity to coordinate platform participants on security issues. In legacy payment platforms, traditional operators can play this central role to promote security by, for example, establishing and enforcing common rules and requirements related to risk management. In the absence of a traditional operator or other entity to coordinate these activities, PSPs may fail to account for the effects of their individual actions on other participants and the overall platform. The effect of these externalities may be particularly severe if a systemwide problem, such as a mass data breach or other system compromise, were to occur. ${ }^{50}$ In a decentralized environment, a central entity may not exist to take actions to halt

\footnotetext{
${ }^{50}$ To the extent that banks or other regulated entities are the PSPs, supervisors may need to consider systemwide risks from very large decentralized systems.
} 
or impede the progression of such an event, nor may such an entity be able to pre-emptively impose safeguards against it.

\subsubsection{Ubiquity}

Competitive pressures may enhance ubiquity in a decentralized environment, but other forces may limit competition and impede ubiquity. To the extent that competitive pressure among PSPs reduces end user fees and increases the provision of payment services, access to faster payment services may increase, which tends to enhance ubiquity. However, some PSPs may maintain pricing power in this environment as a result of product differentiation, switching costs for end users, or other factors. As a result, a decentralized environment might still involve high fees, decreasing adoption or usage and limiting ubiquity.

Beyond fees, opposing forces in the decentralized case may amplify or diminish challenges to ubiquity related to fragmentation. On the one hand, because of network effects, a large number of small PSPs with small client bases must interoperate to offer useful payment services. This dynamic increases incentives to coordinate on interoperability. Moreover, certain costs related to interoperability may be lower in a decentralized environment if individual PSPS can use the widely available underlying technologies to facilitate payments among them. This possibility contrasts with an operator-based scenario in which PSPs would need to participate separately in operator arrangements, with ubiquity depending on the ability of a single operator to capture a significant share of the market, multiple operators to interoperate, or end users to participate in multiple platforms. As a result of these various forces, the decentralized environment may feature less fragmentation.

On the other hand, despite access to widely available, low-cost facilities or technologies, a large number of PSPs lacking an operator or some other type of organization to set common rules and standards could find coordination more difficult, increasing the likelihood of fragmentation. As noted in the discussion of efficiency, in the absence of traditional operator, PSPs would need to deploy alternative methods to exchange payments with one another. Establishing such links may be difficult, particularly if PSPs have difficulties coordinating on common rules, standards, or protocols for the exchange of payments. This problem may be exacerbated if network externalities are not internalized in the decentralized environment. Absent a central operator or other type of organization to consider the entire network for faster payments, individual PSPs or groups of PSPs may not account for the full effect of a comprehensive network on the value of a service. Such a possibility could lead certain PSPs to choose unilaterally not to participate in a broad decentralized arrangement. Alternatively, groups of PSPs, such as a small number of large entities, may focus on connections with each other. 


\section{Considerations for promoting outcomes in line with policy objectives}

The above discussion illustrates a few key issues that can arise in three hypothetical market structures in the faster payments market. A common theme is that many of these issues can be addressed or mitigated through some degree of coordination among payment stakeholders. In the multi-operator and decentralized environments, coordination among suppliers on interoperability may help prevent or alleviate fragmentation, thereby promoting ubiquity. In all three environments, coordination between payment system stakeholders on rules and standards may also mitigate challenges, and effective governance arrangements that provide mechanisms for coordination and decisionmaking can help facilitate industry-wide initiatives. In the decentralized environment, given the lack of a central operator, the presence of an entity or structure that serves in a coordinating role would be necessary to achieve policy objectives. Beyond coordination, there may be a role for public authorities to protect the public interest in all three environments.

This section begins with a discussion on different aspects of coordination arrangements around interoperability, rules and standards, and governance, and it concludes on the role of public authorities in the faster payments market. Across each of these topics, the discussion focuses on promoting outcomes in line with public policy objectives.

\subsection{Interoperability}

Interoperability across payment platforms may help promote public policy objectives in the faster payments market. The term "interoperability" is commonly used in the payments industry to refer to the technical compatibility between multiple platforms that enables exchange of payments across platforms (without the need for end users to participate in more than one platform). ${ }^{51}$ In the discussion that follows, unless otherwise stated, the term interoperability is used according to this common industry definition. In reality, interoperability between platforms falls along a spectrum of compatibility: from no interoperability whatsoever, to a limited interconnection at some point in the payment processing chain (which may or may not involve the exchange of payments across platforms), to full, seamless integration between platforms. In order for separate platforms to be seamlessly coordinated, other forms of interoperability may be required, such as business interoperability, which establishes common roles and responsibilities of different parties in the payments chain. Box 4 provides a few examples of interoperability arrangements in the United States. If technological developments reduce or eliminate the traditional role of the operator, interoperability across PSPs would become an important consideration.

\footnotetext{
${ }^{51}$ Interoperability is aided by the use of common standards and supporting rules.
} 
Box 4: Spectrum of interoperability across payment platforms

Closed-loop platforms (no interoperability): Several person-to-person (P2P) wallet platforms currently provide fast payment capabilities in the United States, offering immediate funds availability for transactions in which the payer and payee are subscribers to the platform (and the payer has sufficient funds available in their wallet to cover the entire transaction amount). Most of these P2P platforms are closed-loop, with no interoperability across platforms; participants are generally not able to send fast payments to customers of other platforms.

Credit cards (limited interoperability): Four major credit card networks provide clearing services for credit card transactions (Visa, MasterCard, American Express, and Discover). These platforms generally do not interoperate in the traditional sense; Discover cards cannot be used to pay a merchant that only accepts Visa. However, the networks coordinate on certain standards, such as EMV chip specifications, that allow merchants to accept multiple networks using a single point-of-sale terminal.

ACH platforms (highly interoperable): The Federal Reserve Banks and The Clearing House rely on each other to process interoperator $\mathrm{ACH}$ payments -- that is, payments in which the originating depository financial institution and the receiving depository financial institution are served by different operators. These interoperator payments are settled by the Reserve Banks. ${ }^{52}$

Interoperability between platforms may promote ubiquity in a multi-operator or decentralized environment. In a fragmented marketplace, particularly one where payers and payees are segmented, interoperable platforms may substantially increase the reach of each platform. However, the degree to which interoperability can promote ubiquity depends in part on the adoption decisions of end users. In the absence of interoperability, ubiquity may still be achieved in a practical sense if end users subscribe to multiple competing platforms (either directly or indirectly through their PSPs). In the case of person-to-business (P2B) credit card payments, for instance, consumers generally subscribe to a subset of the four major card networks through issuing banks. Despite a lack of interoperability between these networks, there is a high degree of ubiquity for credit card payments in the United States today because merchants tend to accept a wide range of networks through their processors or acquiring banks. ${ }^{53}$ However, maintaining access to multiple platforms may be costly, reducing efficiency.

A lack of interoperability may be more limiting to ubiquity in the person-to-person (P2P) market if individuals subscribe to only one or a few of several operators. As discussed in box 4, many closed-loop P2P platforms currently provide real-time payment options for subscribers within their end-user networks, but at this point, these platforms do not deliver ubiquitous faster payments in the United States. Interoperability across these platforms could help close this gap but, as discussed later in this paper, faces significant obstacles.

\footnotetext{
${ }^{52}$ For more information, see Board of Governors of the Federal Reserve System (2016), "The Fed - Automated Clearinghouse Services," https://www.federalreserve.gov/paymentsystems/fedach about.htm.

${ }^{53}$ See Fumiko Hayashi (2006), "A Puzzle of Card Payment Pricing: Why Are Merchants Still Accepting Card Payments?" Review of Network Economics, vol. 5 (1), pp. 144-74. Hayashi notes that merchants tend to accept as many card networks as possible because they are generally hesitant to reject consumers' choice of payment and fixed fees of acceptance are low.
} 
A historical barrier to ubiquity in the payments market that may be relieved through interoperability relates to financial access. Approximately 7 percent of households in the United States are unbanked and lack access to payment services requiring a bank account. ${ }^{54}$ If the faster payments market evolves such that different platforms serve the banked and unbanked populations - as product differentiation might predict - interoperability may be required to enable faster payments between these groups. Such a scenario could arise if one operator with banks as service providers competes against another operator primarily serving the unbanked. Ensuring access to faster payments for low-income consumers (those likely to be unbanked) is important because those consumers are expected to benefit significantly from near-real-time funds availability. 55

Interoperability arrangements may also promote resiliency in a multi-operator environment. An aspirational example would be a scenario in which operators mutually provide continuity of clearing and settlement services, allowing PSPs to exchange payments even when one operator experiences an operational failure. Of course, non-interoperable platforms can provide some level of resiliency because end users subscribing to multiple operators can switch to an alternative platform if their first choice becomes unavailable. However, redundancy arrangements via interoperation may provide an alternative path for transactions regardless of end-user adoption decisions. Even short of full redundancy, some degree of interoperability may help ensure continuity of basic services during a service disruption to one platform.

Achieving interoperability is not easy; it requires a high degree of coordination and planning, and a number of obstacles may limit or prevent interoperation. Fundamental inconsistencies in design may have significant implications for interoperability, both across operators in a multioperator environment and across PSPs in a decentralized environment. Variation in message formats, encryption standards, platform rules, and other processes represent design features that may affect interoperability. Because these issues often involve rules and standards, they are discussed in more detail in section 4.2. However, two particular design features settlement mechanisms and directory services - warrant particular attention in terms of their implications for interoperability.

Interoperability may be limited by differences in settlement design across payment platforms. One scenario would be a platform with real-time settlement and another with deferred settlement (with immediate funds availability derived from a credit extension). A payment from the deferred settlement platform to the real-time settlement platform might not result in immediate availability of funds for the payee if there were no provision for the extension of

\footnotetext{
${ }^{54}$ Federal Deposit Insurance Corporation (2016), 2015 FDIC National Survey of Unbanked and Underbanked Households, https://www.fdic.gov/householdsurvey/2015/2015report.pdf.

${ }^{55}$ Fumiko Hayashi (2016), "Access to Electronic Payments Systems by Unbanked Consumers," Federal Reserve Bank of Kansas City, Economic Review, vol. 101 (Q3), pp. 51-76, https://www.kansascityfed.org/ /media/files/publicat/econrev/econrevarchive/2016/3q16hayashi.pdf.
} 
credit across operators. Box 5 provides additional discussion on how settlement issues may affect interoperability in the faster payments market.

\section{Box 5: Settlement models for faster payment platforms and implications for interoperability}

Settlement for faster payment platforms requires arrangements that transfer funds between platform participants based on the payment activity of their customers. As discussed in the CPMI report on fast payments, settlement arrangements for faster payments can vary in a number of ways. ${ }^{56}$

A key difference among settlement models is timing. Although all faster payment platforms provide realtime (or near-real-time) funds availability to the payee, some platforms employ real-time settlement, whereas others use deferred settlement. In the former case, settlement between PSPs coincides with the provision of funds to the payee. In the latter case, settlement between PSPs, often on a net basis, occurs after the provision of funds to the payee. Deferred settlement creates a credit exposure for the payee's PSP because it releases funds to the payee before receiving funds from the payer's PSP. This and other differences in settlement models affect interoperation. ${ }^{57}$

Interoperation, in which payments originated in one platform are delivered in another, requires some arrangement for settlement between PSPs of the different platforms. One arrangement involves a direct settlement connection between two operators; for example, one operator could participate in the other's settlement arrangement. Another arrangement might involve a financial institution that separately participates in each platform's settlement mechanism. In the latter case, the intermediating institution serves as a "settlement bridge." If allowed, such bridge institutions might provide for other aspects of interoperation, such as transmitting clearing messages. In a decentralized environment, a common underlying settlement service may effectively provide this settlement bridge across PSPs.

Timing differences in settlement models may affect the speed of transactions that cross multiple platforms. Small delays in availability of final funds to the payee may occur if a bridge institution delays sending or settling a payment to the payee until funds are settled from the payer. If both platforms employ real-time settlement, delays may be small. If the payer's platform employs deferred settlement, delays may be more substantial.

Beyond practical issues, a number of risks may arise depending on the settlement arrangements for interoperation. Because deferred settlement involves credit risk for the payee's PSP, either a destination operator or bridge institution may have to assume this credit risk if payments are to be delivered in real time. This possibility could give rise to a concentration of credit risk. In addition, a bridge institution participating in multiple platforms for the purposes of interoperability may concentrate operational risk, particularly if the bridge is the only connection between platforms (that is, it becomes a single point of failure).

Directory services is another area where design differences may influence interoperation. Directory services enable a payer to transfer funds to a payee without knowing details of the payee's account information by providing an alias, such as an e-mail address or phone number. These services also enable the payer's operator or PSP to route payment messages or clearing

\footnotetext{
${ }^{56}$ CPMI, Fast Payments.

57 Settlement may have other effects as well. As the CPMI report discusses, real-time settlement can be demanding in terms of liquidity and may require liquidity management by PSPs on an ongoing basis. In contrast, deferred settlement does not have the same liquidity requirements but generates credit risk through the provision of funds to the payee by the payee's PSP before it receives funds. Various tools, discussed in the CPMI report, are available to manage the risks associated with different settlement models.
} 
information to an appropriate entity, which then forwards the information to the payee's PSP. If directories that include a subset of end users or PSPs are developed separately and these directories are not broadly accessible to different operators or PSPs, the ability to route payments across different platforms may be limited. ${ }^{58}$

Not all barriers to interoperability derive from technical differences - even if platforms are designed to interoperate, various strategic barriers may persist. Faster payment operators that also operate legacy platforms may block or limit interoperation of faster payments in order to protect the profitability of their legacy businesses. Indeed, incumbents may have incentives to block interoperation with entrants more generally. Intellectual property rights, such as patents associated with a standard, may allow incumbents to exclude rivals through the establishment of proprietary standards. These proprietary standards contrast with common, open standards that may facilitate interoperability, as discussed in the next subsection.

Another notable example of a strategic barrier to interoperability is access pricing - the fees charged by one firm for processing payments from others. ${ }^{59}$ In the faster payments market, a firm with captive customers might charge other firms high access prices to exchange payments with those customers. In the dominant-operator environment, the dominant operator may charge excessive access fees to a new entrant that wants access to the dominant operator's customers. ${ }^{60}$ Such fees may serve as a barrier to entry, limiting competition in the market. In the multi-operator and decentralized environments, a firm may be incented to lure new customers by offering them subsidies in order to charge high access fees to competitors. ${ }^{61}$ Access fees may not be an issue if firms are approximately equal in their characteristics; in this case, the firms may negotiate low or zero access fees because symmetry implies that any such fees should net out near zero.

\subsection{Rules and standards}

While interoperability may help promote public policy objectives in the multi-operator and decentralized environments, it requires coordination on various rules and standards - including technical specifications, message formats, directory services, and policies governing transactions that move across platforms. Beyond interoperability, coordination on rules and standards can promote public policy objectives in the faster payments market in all three market structure environments considered in this paper.

\footnotetext{
${ }^{58}$ A few directory models, including a federated directory or single national (central) directory, may help address these issues.

${ }^{59}$ Access pricing also has effects beyond issues related to interoperability. For example, access pricing affects fees for end users and, as a result, influences adoption and use decisions.

60 This possibility is referred to as the one-way access pricing problem. See Jean-Jacques Laffont and Jean Tirole (1999), Competition in Telecommunications.

61 This phenomenon is one version of a two-way access pricing problem. See Mark Armstrong (2002), "The Theory of Access Pricing and Interconnection," in Martin E. Cave, Sumit K. Majumdar, and Ingo Vogelsang, eds., Handbook of Telecommunication Economics, vol. 1 (Amsterdam: Elsevier), pp. 297-386.
} 
Interoperability requires some level of agreement on rules and standards pertaining to how transactions are processed across platforms. Depending on how platforms interoperate, coordinated rules may, among other things, specify the roles and responsibilities of various stakeholders, including operators, PSPs, vendors, and end users, allocate liability, and establish processes for the resolution of fraudulent/erroneous transactions (consistent with any applicable statutes and government regulations). Rules governing credit and liquidity requirements may be particularly important in interoperability arrangements that concentrate credit and operational risks. In the decentralized environment, coordination on common peerto-peer messaging protocols and other communication tools may help support the broad exchange of payments between PSPs.

Coordination on standards, particularly related to messaging, is also critical to achieve many technical aspects of interoperability. Although adoption of common standards can aid interoperability, additional coordination may be necessary. For example, payment platforms worldwide are increasingly adopting ISO 20022, yet the flexibility of the standard means that different platforms can implement it in different ways. ${ }^{62}$ Consequently, unless there is coordination to agree on the details surrounding implementation, a translation or other ancillary service may still be needed for platforms to exchange messages. These additional steps may hinder adoption of faster payments by business end users who expect faster payments to deliver straight-through processes in which detailed remittance information is transferred seamlessly along with a payment.

Additionally, international standards for payment messages, such as ISO 20022, may help facilitate interoperability with faster payment platforms internationally. This capability may increase the efficiency of cross-border payments and encourage adoption of faster payments by end users in an increasingly global economy. However, differences in implementation may also affect interoperability for cross-border payments.

Even if interoperability were not an objective, coordination on rules and standards can provide significant benefits in the faster payments market. Common standards related to security (for example, end-to-end encryption and multifactor authentication) can help provide a baseline level of security across all relevant platforms in the industry. Common rules or guidelines related to end-user experiences can help ensure baseline levels of service and features expected from all faster payment platforms, such as the timing of funds availability and enduser protections. These baseline measures can help build and maintain public confidence in faster payments capabilities. In the decentralized environment, in the absence of a central

\footnotetext{
62 ISO 20022 is an international standard pertaining to payments messages consisting of a harmonized set of XML messaging standards across major financial services domains (Cash, Securities, Trade, Card and Foreign Exchange) based on a shared data dictionary and business process model. It has emerged as an enabler of a single, common "language" for global financial communications. It is developed by the International Organization for Standardization.
} 
operator with incentives to maintain a platform from end to end, coordinated rules and standards are critical to help ensure that PSPs and other participants have incentives to support the smooth functioning of a platform or platforms.

Rules and standards that reflect broad stakeholder input may also help promote public policy objectives in all three market structure environments. Better outcomes may be achieved if platforms are based on open, consensus-based standards, rather than proprietary standards. Open, consensus-based security standards may benefit from an open-vetting process, which can help identify flaws before development and implementation. Rules that reflect broad stakeholder input from a wide range of PSPs, end users, public authorities, and other stakeholders in may help foster balanced allocation of benefits and costs of faster payments across participants. Moreover, rules that are balanced for both large and small PSPs may promote a level playing field and encourage competition at the PSP level, thereby promoting efficiency.

In the multi-operator and decentralized environments, the existence of different rule sets can generate various interactions. When stakeholders coordinate on rules, careful consideration of these interactions is key to achieving positive outcomes. While platform-level rules provide important flexibility in governing processes specific to an individual platform, these rules may have spillover effects to other platforms, which could give rise to anticompetitive concerns. For example, an operator's rule that prevents or limits the ability of an entity, such as a PSP, to participate in another operator's platform may reduce competition. Industry-level rules (that is, rules applying to all platforms) may help mitigate these concerns by establishing a level playing field between faster payment providers, including operators, PSPs, and other intermediaries. However, overly prescriptive rules at the industry level may limit the ability of providers to manage individual platforms effectively and reduce incentives to innovate.

\subsection{Governance}

Coordination on common rules and standards, interoperability, and other initiatives can promote public policy objectives in the faster payments market, but outcomes depend in part on the way in which stakeholders coordinate and make decisions. Governance refers to institutional and other arrangements that allow for coordination and decisionmaking.

Many industry stakeholders - including end users, service providers, financial institutions, and operators - participate in the payments process. Governance arrangements can play an important role in bringing these stakeholders together to coordinate on initiatives that may advance efficiency, safety, and ubiquity. With respect to safety, for example, payment platforms often interconnect with many other systems, including other payment platforms, inventory management systems, and consumer devices. Governance arrangements that provide some degree of coordination among stakeholders on safety issues may be required to 
secure this interconnected ecosystem. ${ }^{63}$ With respect to ubiquity, governance arrangements can provide mechanisms for operators or PSPs to coordinate on issues related to interoperability, including rules and standards that govern the way transactions are exchanged between intermediaries as well as directory services. ${ }^{64}$

Governance arrangements may exist both within and across platforms. Historically, governance arrangements over individual platforms have been administered by central operators, reflecting their traditional role in providing centralized functions that allow for the exchange of payments between PSPs. ${ }^{65}$ Additionally, a few cross-platform governance structures have emerged that largely focus on setting rules and standards in cases where interoperability or access-device compatibility was desirable. In the decentralized environment, a key question is how to organize governance arrangements, given that a diffuse set of PSPs provide for faster payments without the support of a central operator. In this environment, the large number PSPs, the potential lack of accountability for overall system maintenance, and the inefficiencies associated with bilateral- or multi-lateral negotiations suggest that a central coordinating governance body or structure would still be needed.

The ability of governance arrangements to promote public policy objectives depends, in part, on how they are structured. Governance structure includes organizational structure, scope, and external relationships. Aspects of organizational structure include membership or the specification of subcommittees. Scope entails which platforms and aspects of those platforms fall under a governance arrangement's remit. External relationships comprise relationships with other governance bodies, standards-setting organizations, and public authorities.

There may be advantages to establishing industry-level governance arrangements in addition to those covering individual platforms. Industry-level arrangements may serve the purpose of bringing all stakeholders to the table to coordinate on initiatives related to the faster payments market broadly, including interoperability across platforms and fraud information sharing, while within-platform arrangements may focus on initiatives or issues specific to an individual platform. The combination can help reduce complexities associated with maintaining multiple

\footnotetext{
${ }^{63}$ One useful basis for organizing such coordination may be the cybersecurity framework from the National Institute of Standards and Technology (NIST), which was recently updated to help organizations working on a joint project better understand cybersecurity needs. See NIST (2017), "Framework for Improving Critical Infrastructure Cybersecurity Draft Version 1.1," January, https://www.nist.gov/sites/default/files/documents////draftcybersecurity-framework-v1.11.pdf.

${ }^{64}$ As discussed in the rules and standards subsection of this paper, interoperability between platforms may require coordination on the implementation details of common standards, such as ISO 20022.

${ }^{65}$ For an introduction to the economic theory of governance, see Oliver E. Williamson (2002), "The Theory of the Firm as Governance Structure: From Choice to Contract," Journal of Economic Perspectives, vol. 16 (Summer), pp. 171-95.
} 
sets of rules and processes while still allowing for differentiation in products or business models. ${ }^{66}$

Governance arrangements may achieve better outcomes if they are transparent, inclusive of a broad range of stakeholders in the payments process, including end users and PSPs of varying sizes, and composed of members with sufficient knowledge and authority to make decisions on behalf of their organizations. Such arrangements may help accelerate the development and adoption of faster payment platforms generally, as well as new standards, technologies, and processes that address the needs of a wide variety of stakeholders.

In evaluating a particular governance arrangement, an important consideration is whether it is structured and administered in a way that promotes the positive effects of competition. While efficient outcomes require some level of coordination, improper coordination among competitors, such as price fixing, market allocation, and other forms of collusion, can lead to anticompetitive harm, including higher prices, lower output, and reduced innovation. Moreover, these activities may violate antitrust laws, which would need to be considered. ${ }^{67}$

Establishing industry-wide governance arrangements early in the faster payments market, possibly even before business plans have been finalized, may be important. Given the pathdependent nature of infrastructure decisions, current decisions about governance may affect future costs and time to achieve industry-wide initiatives.

\subsection{Role of public authorities}

Public authorities, including central banks, can play an important role in promoting efficiency, safety, and ubiquity in retail payments. In other jurisdictions, public authorities have taken on a variety of roles in faster payments, including catalyst for change, regulator, supervisor, and service provider.

Public authorities may act as catalysts for change in the faster payments market by facilitating coordination among stakeholders on initiatives like interoperability, rules, standards, and governance. Such a role may include facilitating discussion between broad stakeholder groups, aligning industry stakeholders on specific objectives to advance public policy goals, and producing analysis and research relevant to these issues.

Regulators and supervisors, pursuant to their statutory authority, play a key role in protecting the public interest. Regulation, as well as supervisory programs, may be designed to limit risk

\footnotetext{
66 Uniform expectations around funds availability and liability across platforms, for instance, may be beneficial.

${ }^{67}$ In addition to consulting legal counsel, payment stakeholders may wish to review "Antitrust Guidelines for Collaboration Among Competitors," published by the Federal Trade Commission and the Department of Justice, which outlines how the agencies analyze antitrust issues raised by collaboration among competitors. See Federal Trade Commission and U.S. Department of Justice (2000), "Antitrust Guidelines for Collaborations Among Competitors," April, https://www.ftc.gov/sites/default/files/documents/public events/joint-venture-hearingsantitrust-guidelines-collaboration-among-competitors/ftcdojguidelines-2.pdf.
} 
exposure and promote security and resiliency. In performing their statutory functions, regulators and supervisors may be guided by cooperatively established principles or industry best practices. For example, the CPMI and the International Organization of Securities Commissions published international risk management and related standards in the Principles for Financial Market Infrastructures (PFMI) for financial systems, including payment platforms, that are systemically important. ${ }^{68}$ To date, no retail payment platforms have been designated as systemically important in the United States; however, these principles, where relevant, may help inform the design of supervisory programs for these platforms or institutions that use them. Besides limiting individual risk exposure, supervisors may gain broader insights on systemic risk by virtue of their supervision of multiple institutions using one or more payment platforms. Regulators and supervisors can also help ensure that individual institutions internalize the effects of their security standards and practices on others.

In addition to promoting security and resiliency, and subject to the authorizing statutes, regulations may be designed to address market power concerns or to protect end users in other ways. Regulations encouraging entry may promote competition and prevent the concentration of market power. For example, a regulation requiring broad licensing of proprietary standards may reduce barriers to entry. Price regulation might be designed to help ensure that a provider with significant market power does not charge excessive or inequitable prices. ${ }^{69}$ Regulations designed to ensure that faster payment platforms incorporate consumer protections may focus on a variety of issues, including privacy, funds availability, and fraud and error resolution protections. ${ }^{70}$ Regulations may include specific rules concerning pricing, product design, and other practices, such as transparency. In some cases, supervisory oversight or the potential for regulation may be sufficient to prevent unfair practices and to protect the public interest. Any regulation, however, may have unintended negative consequences, such as lower output or reduced incentives to innovate.

As discussed in the CPMI report on fast payments, central banks may play a variety of service provider roles in supporting the provision of faster payments. Central banks traditionally operate a country's real-time gross settlement (RTGS) system, which can support settlement for faster payment platforms. As a jurisdiction deploys faster payment capabilities, a central bank may decide not to implement any changes to its existing services, or it may modify services in a variety of ways to support faster payments. For example, a central bank may make modest changes to existing services (for example, extending RTGS operating hours), provide new or

\footnotetext{
${ }^{68}$ CPMI and Technical Committee of the International Organization of Securities Commissions (2012), Principles for Financial Market Infrastructures, http://www.bis.org/cpmi/publ/d101a.pdf.

${ }^{69}$ Many natural monopoly markets are regulated to help ensure fair and equitable pricing.

${ }^{70}$ For a discussion of consumer protection issues that may apply to the faster payments market, see Consumer Financial Protection Bureau (2015), "Consumer Protection Principles: CFPB's Vision of Consumer Protection in New Faster Payment Systems," July 9, http://files.consumerfinance.gov/f/201507 cfpb consumer-protectionprinciples.pdf.
} 
enhanced capabilities to support faster payments, or serve as an operator of a faster retail

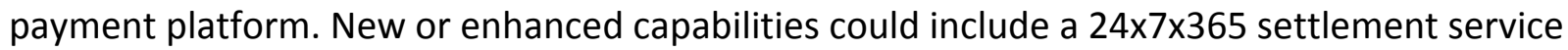
that participating PSPs can use to settle fast payments for their customers.

As in any nascent market, the role of public authorities may need to change as technology and the market evolve. Careful, inclusive, transparent, and responsive policy processes may help identify roles for public authorities that promote policy objectives.

\section{Conclusion}

Economic and technological considerations will play an important role in shaping the U.S. faster payments market. It is too early to tell how the market will evolve in the long run - a variety of market structures may emerge, each with a unique set of features that affect the public policy goals of safety, efficiency, and ubiquity. In light of the rapid evolution of technology, consideration of and action to achieve these objectives should be forward-looking and flexible. The direction the industry takes regarding interoperability, rules, standards, and governance, as well as the role that public authorities play, will each affect the future path of the industry. Because of the tendency for path dependence in the development of a payment market, a forward-looking perspective informed by a wide range of stakeholders is particularly relevant at this juncture. 